\title{
PERCEPTIONS AND ATTITUDES OF AIRLINE EMPLOYEES TOWARDS DIVERSITY. A QUANTITATIVE ANALYSIS
}

\author{
Maria P. Doumi \\ School of Business Administration, University of the Aegean, Chios, Greece. \\ Ioannis Vellios \\ School of Social Sciences, Hellenic Open University, Patras, Greece \\ Konstantinos M. Mouratidis \\ School of Business Administration, University of the Aegean, Chios, Greece
}

\begin{abstract}
As the world tourism market is continuously changing, travel by air is considered the most widespread mode of mass international tourism. Considering new ways of management that airlines need to adopt in order to have a well trained and qualified management team, this survey explored the attributes of airline employees and their interactions with diverse customers and identified the sufficient role of employees' training and the advantages of diversity management. Simple random sampling method was applied to gather 309 airline employees' questionnaires on their attitudes towards diversity. Descriptive and inductive analyses were used to present the obtained data. Principal Component Analysis was conducted to predefine three factors. Pearson correlation coefficient was applied to present the direction of the relationship between extracted factors and employee's occupational status. Authors' findings emphasise that airline employees seek a workplace with a friendly atmosphere that respects the diversity of employees and customers and they in their turn support airlines to operate over the comfort zone to achieve organisation's goals and customers' satisfaction. As the world keeps advancing, planning a diversity strategy should be the first step any modern-day organisation should explore prior to embarking anything related to a diverse workplace.
\end{abstract}

\section{KEYWORDS}

Airlines, Diversity, Employees, Training, Multicultural Working Environment 


\section{INTRODUCTION}

The airline industry is considered integral part of tourism development, while air travel contributes to the phenomenon of mass international tourism (Holloway \& Humphreys, 2016). Nowadays, travel by air is the most widespread mode for international tourism and airlines are forming a tourism development within a destination via the tourists they transfer from one place to another. However, over time the upward trend of air travel was interrupted due to the appearance of the pandemic and the negative consequences of the spread of the corona virus. According to ICAO's annual global statistics in 2018, for instance, transportation globally exceeded 4.3 billion passengers only through scheduled flights (6.4 percent higher than the previous year), while the number of departures reached 37.8 million in 2018 (3.5 percent increase). According to IATA (2020), international passenger traffic fell by $-91.9 \%$ year-on-year in July 2020, and international air travel demand remained broadly sluggish for all regions. Globally, passenger demand for air travels remains slow due to the weak consumer confidence along with the unstable epidemic situation and the negative impacts of the spread of COVID-19, which are expected to reduce passenger revenues from $\$ 612$ billion in 2019 to $\$ 241$ billion in 2020 (IATA, 2020). Taking into consideration the aforementioned ever-changing reality, airlines try to become more competitive in the global market and seek for methods and patterns in order to establish international and domestic air travels. In this framework, this paper focusses on the role of diversity in the airline industry and the supportive role of the training among airline employees. In the light of airline employees' perceptions and attitudes towards diversity, this work attempts to explore the diversity as a strategic management tool, the role of training on a diversity agenda and its importance for the maintenance of a positive and supportive working environment.

Diversity refers to different perspectives of personal beliefs and ideas (Esty et al., 1995; Patrick and Kumar, 2012) enhanced by socioeconomic, environmental, and technological factors (Cletus et al., 2018). Considering the new era of globalisation, immigration, and the mass movement of passengers from one place to another, airlines tend to explore management practices and prioritise workplace diversity in order to accommodate employees' and passengers' needs. In the airline industry, according to authors' knowledge, the workforce diversity and the challenges arising from the diverse background of employees and customers have rarely been studied directly. Due to this fact, the research explored the attributes of airline employees and their interactions with customers for airlines to align with the sustainability agenda and understand that advantages of diversity management to accommodate the needs of 
both parties. Furthermore, the key contribution of this survey is the strategic directions it provides to airline supervisors and managers so that they can focus their efforts on the development of human resources in areas, such as flexibility, adaptability, and capability.

\section{LITERATURE REVIEW}

\subsection{Diversity and Workplace Diversity}

For decades, diversity was considered an operational characteristic, whilst new laws and procedures were adopted to face this matter. At workplace -but not exclusivelythe term refers to the characteristics that distinguish and promote the difference of others with respect to age, race, gender, class, ethnicity (Esty et al., 1995), sexual orientation, political and religious beliefs, physical abilities, marital status, socioeconomic status, etc. (Velazquez, 2017). Over time, an extensive literature has developed on workplace diversity and its crucial importance in business and organisational management. Previous studies (Walia and Malik, 2015; Green et al., 2002) have recognised that workplace diversity provides employees with varied capabilities, which ensure effective strategic planning and provide a safe climate for the achievement of organisational goals. A diverse workplace allows an organisation to effectively implement its strategic plans (Kapoor, 2011), provides a competitive advantage for the promotion of facilities and services by employees and allows an effective dealing with stereotypes that some individual employees might have.

\subsection{Diversity in the Airline Sector}

By definition, airlines promote a multicultural aspect of employment. Employees not only offer services to an international range of passengers but they also work with multicultural colleagues and tend to adapt into new cultures and societies that they come across with on a daily basis. In the airline industry everything is related to safety and security, while passenger services focus on passenger comfort. Taking into consideration the diverse profile of passengers that are carried on an aircraft, airlines are designing their products as per their needs in order to bridge the diversity gap that might arise throughout their experience, while at the same time they become competitive in the aviation market. An airline that has a well trained and qualified management team creates a self-respect feeling within the airline staff community. However, the staff has to create a bond between the team and their passengers as this will differentiate any airline from its competitors, while trust and inclusion are characteristics of an excellent team. A research published at the Department of Transport in the United States shows that in the first 10 months of 2016, non 
awareness of diversity towards others recorded an increase of $37 \%$ in the airline industry. Several airlines around the world train their employees on being empathetic and using their feelings in order to understand and assist passengers no matter where they come from.

\subsection{Diversity as A Strategic Management Tool}

As the world tourism market is continuously changing, Diversity Management becomes a process intended to create and maintain a positive work environment, where the similarities or differences of individuals are valued (Patrick and Kumar, 2012). Diversity Management consists of a significant organisational challenge for supervisors intending to maximise the organisation's strategic goals and exceed its targets (Green et al., 2002). In the tourism industry, diversity, sustainability, and business are intrinsically linked, as organisations are required to investigate and exploit employees' and customers' diversity in a critical way for their success. It is observed, that in international carriers, leadership consists of a multicultural profile. Thus, this is equivalent to a diverse hierarchy that adopts all possible leadership scenarios to promote a can-do attitude in both teams and services provided to their audience ((Dipak Prasad Bastola, 2011 ). The study of Robinson and Dechant (1997) revealed that organisations can increase their attractiveness to present and future employees, partners, and customers by promoting workplace diversity. Therefore, Ozbilgin and Tatli (2008) suggested that a successful diversity management and a resulting improvement in organisational performance are positively correlated. In the light of the reported facts and following a human-centric approach of employees from different backgrounds, this survey addresses the need for the exploration of employees' perceptions towards workplace diversity into the airline industry, which is so far lacking in scientific literature.

\subsection{Diversity in Workplace: The Effective Role of Employees' Training}

In order for airlines to seek diversity, promote inclusion and enhance the values derived from employees' similarities or differences they need to adapt proper training plans to their employees, as the opposite is expected to have negative consequences for a brand. Hence, employees' training contributes to the awareness of diversity at workplace. Keese (2020) stated that "mandatory diversity training for managers should be incorporated as part of a developmental learning process to ensure managers can effectively deal with diversity issues". Thus, airline managements need to decide on which direction the company is focusing as this could be used as a strong tool to achieve a well-known brand. In general, airlines are focused mostly in safety and 
security, however a mass number of passengers rely and choose a carrier based on the product delivered. Crew has to be adaptable and flexible in all scenarios. These two definitions can be achieved by using a well- planned educational programme to implement and to promote diversity and situational awareness of team members while at workplace (Yu-Hern Chang, 2013). A company that has highly qualified and well trained staff will contribute to the development of the organisation, At the same time, the managers of such an airline, who understand the importance of cultural diversity, are trained on how to handle conflicts deriving from diverse backgrounds (Keese, 2020). Taking into consideration that the airline industry is very demanding and the turnover of employees is frequent, training programmes for airline employees provide significant opportunities for the sustainability of airline companies. Having an employee training programme means your employees are constantly learning new skills or improving their existing skills that increase productivity, reduce mistakes, build confidence, and create a better workplace (Deans, 2018). Using the right skills of employees to meet market demands, the company can increase productivity, minimise risks, contribute to self development (both for the actual individuals and the company), present a competitive image and offer a pleasant working environment. A training programme allows employees to strengthen the areas and the fields that need improvement (Deans, 2018) while it also promotes the development and growth of the airline and its staff.

\section{THEORETICAL AND/OR EMPIRICAL CONTRIBUTION}

To explore research objectives, a structured questionnaire was used, which consisted of 15 five-scale as well as close-ended questions referring to the respondents' demographic profile. A simple random sampling method was applied to gather 309 questionnaires on airline employees' attitudes towards diversity. Descriptive and inductive analyses or inferential statistics (correlation coefficient) were used to present the obtained data, which were collected through online surveys (April to June 2019) and were analysed by SPSSv.25. A Principal Component Analysis (PCA) was conducted to classify airline employees' attitudes towards diversity into three components (Table 2), which accordingly contributed to the formulation of research hypotheses (Figure 1). PCA was used mainly in exploratory data analysis as a dimensionality-reduction method that is often used to compute principal components and to reduce the dimensionality of large datasets. 


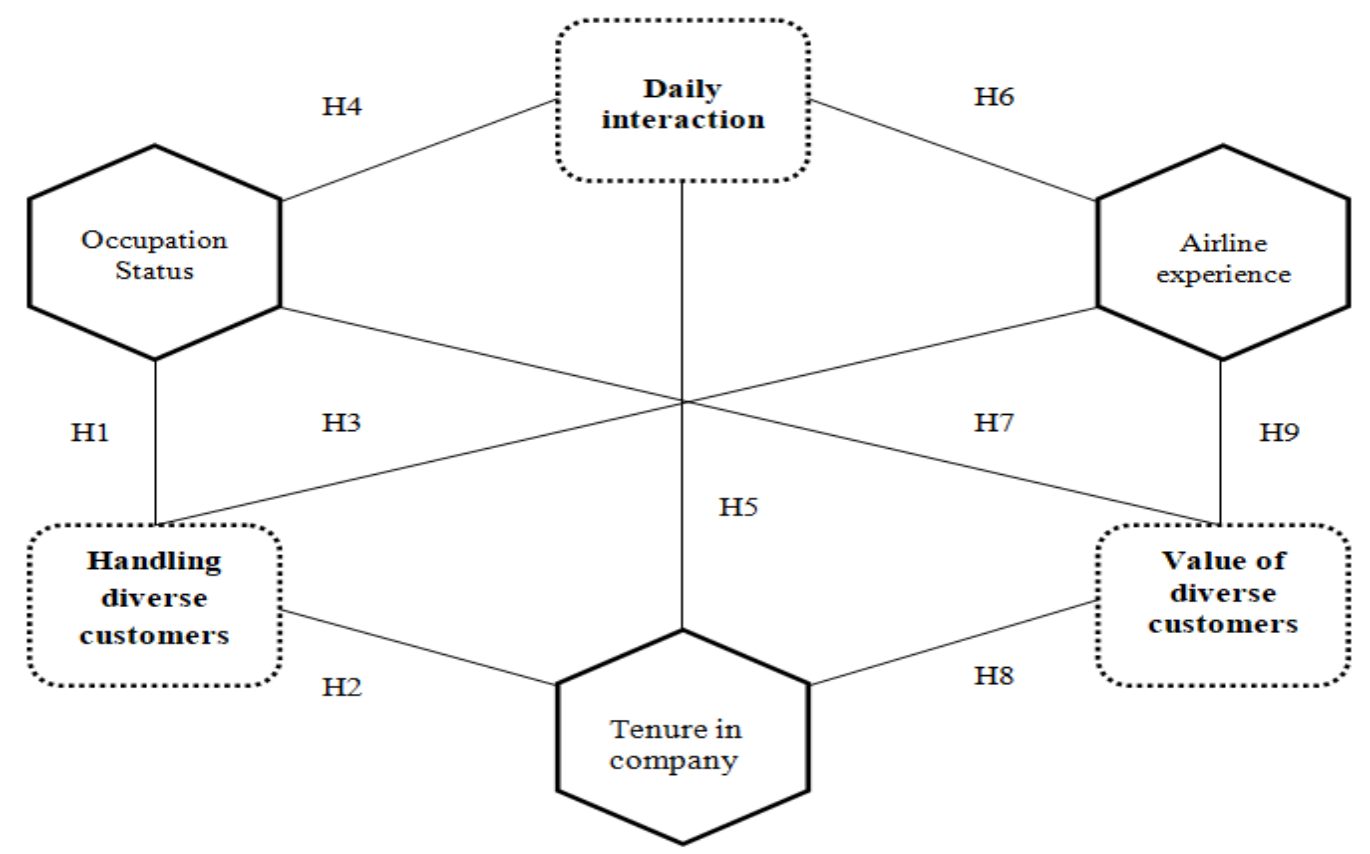

Figure 1. Operating model

\section{RESULTS}

\subsection{Airline Employees' Profile}

Most airline employees are female (74.1\%), while the respondents aged between 25 and 34 are the largest group ( $68.9 \%$ of the sample size). The respondents aged between 18 and 34 consist of the youngest category of the sample accounting for 76.4\% (Table 1).

Table 1. Descriptive Statistics for the Demographic Profile of Airline Employees' $(N=309)$

\begin{tabular}{|c|c|c|c|c|c|}
\hline \multirow{3}{*}{ Gender } & & $\%$ & & & $\%$ \\
\hline & Female & 74.1 & \multirow{2}{*}{ Flight Mode } & \multirow{2}{*}{$\begin{array}{l}\text { International } \\
\text { Domestic }\end{array}$} & 90.6 \\
\hline & Male & 25.9 & & & 9.4 \\
\hline \multirow{4}{*}{ Age } & $18-24$ & 7.4 & \multirow{4}{*}{$\begin{array}{c}\text { Occupational } \\
\text { Status }\end{array}$} & Full Time & 82.5 \\
\hline & $25-34$ & 68.9 & & Part Time & 2.6 \\
\hline & $35-44$ & 17.5 & & Causal & 0.3 \\
\hline & $45+$ & 6.1 & & Contract & 14.6 \\
\hline \multirow{4}{*}{$\begin{array}{l}\text { Education } \\
\text { Level }\end{array}$} & & & \multirow{4}{*}{$\begin{array}{l}\text { Job } \\
\text { Level }\end{array}$} & Flight Attendant & 78.0 \\
\hline & Basic & 13.9 & & $\begin{array}{l}\text { Cabin Crew or in } \\
\text { Training }\end{array}$ & \\
\hline & Tertiary & 52.8 & & In-flight Cabin & 13.6 \\
\hline & $\begin{array}{l}\text { Master's } \\
\text { degree }\end{array}$ & 33.3 & & $\begin{array}{l}\text { In-flight Cabin } \\
\text { Manager }\end{array}$ & 8.4 \\
\hline \multirow{5}{*}{$\begin{array}{c}\text { Airline } \\
\text { Experience }\end{array}$} & $<1$ year & 7.4 & \multirow{5}{*}{$\begin{array}{l}\text { Tenure in } \\
\text { airline } \\
\text { company }\end{array}$} & $<1$ year & 11.7 \\
\hline & $1-3$ & 16.8 & & $1-3$ & 21.7 \\
\hline & $4-6$ & 32.0 & & $4-6$ & 33.7 \\
\hline & $7-9$ & 17.8 & & 7-9 & 15.9 \\
\hline & $10>$ & 25.9 & & $10>$ & 17.2 \\
\hline
\end{tabular}


Regarding the educational level, $52.8 \%$ of airline employees have graduated tertiary education, while $33.3 \%$ of them have master's degrees. As for their occupational status, $78.0 \%$ of the sample worked as flight attendants, mainly full time (82.5\%); while nine out of ten were employed in international flights. After summing some group cases, it is observed that $67.0 \%$ of the sample respondents have been working with their current airline company for up to six years, while one out of two has worked in the airline industry for over seven years.

\subsection{Principal Component Analysis}

Principal Component Analysis (PCA) was adapted to divide fifteen diversity items into three principal factors which express airline employees' diversity attitudes (Table 2). The Kaiser-Meyer-Olkin Measure of Sampling Adequacy (.883) and Bartlett's Sphericity test statistic (.000) supported the implementation of the PCA method. A Varimax with Kaiser Normalisation rotation method was conducted to classify each item as a correlate variable with high loading on only one component. Three factors of airline employees' perceptions were recognised, which explain $54.2 \%$ of the total variance of those perceptions. The Rotation Sums of Squared Loadings showed that the first factor named: "Handling diverse customers" accounts for $36.1 \%$ of Variance, the second factor titled: "Daily Interaction with diverse customers" accounts for $17.8 \%$ and the last factor named: "Understanding the value of diverse customers" accounts for $14.9 \%$ of Variance. The aforementioned factors have eigenvalues greater than 1.0 which satisfy the requirement of the Parallel Analysis (Pallant, 2007).

Reliability analysis was applied to explore the internal consistency of the overall scale. Cronbach's a (or coefficient alpha) as a measure of scale reliability was used to explore if multiple-question Likert scale surveys are reliable. Nevertheless, a "high" alpha value does not imply that the measure is unidimensional but may mean that the items in the test are highly correlated. In general, a score for dichotomous or Likert scale questions of more than 0.70 is usually acceptable, while many authors suggest values higher than 0.80 . Cronbach's alpha statistic presented the reliability of handling diverse customers (.859), daily interaction with diverse customers (.774) and understanding the value of diverse customers (.769) measurement scale. The mean scores and standard deviations of these three factors for both parties are presented in Table 2. 
Table 2. Airline Employees' Diversity Components

\begin{tabular}{|c|c|c|c|c|c|}
\hline & \multicolumn{3}{|c|}{ Components } & \multirow{3}{*}{$\begin{array}{c}\text { Mean } \\
3.75\end{array}$} & \multirow{3}{*}{$\begin{array}{l}\text { SD } \\
.809\end{array}$} \\
\hline & 1 & 2 & 3 & & \\
\hline \multicolumn{4}{|l|}{ Handling diverse customers } & & \\
\hline $\begin{array}{l}\text { Crew of different background interacts easily } \\
\text { with diverse customers }\end{array}$ & .722 & & & 3.86 & 1.264 \\
\hline $\begin{array}{l}\text { Crew discourages discrimination towards } \\
\text { customers }\end{array}$ & .716 & & & 3.65 & 1.317 \\
\hline $\begin{array}{l}\text { Estimating that crew leader takes appropriate } \\
\text { action in case a diversity gap is noticed among } \\
\text { colleagues and customers }\end{array}$ & 623 & & & 3.91 & 1.259 \\
\hline $\begin{array}{l}\text { Crew appreciates customers with different } \\
\text { race/ethnicity }\end{array}$ & 617 & & & 3.51 & 1.260 \\
\hline $\begin{array}{l}\text { Treating everyone equally while I am dealing } \\
\text { with customers }\end{array}$ & .558 & & & 3.97 & 1.131 \\
\hline $\begin{array}{l}\text { Understanding racial/ethnic background of } \\
\text { customers }\end{array}$ & .468 & & & 3.28 & 1.330 \\
\hline $\begin{array}{l}\text { Understanding colleagues' }{ }^{\prime} \quad \text { different } \\
\text { perspectives towards diverse customers }\end{array}$ & .454 & & & 4.06 & 1.174 \\
\hline \multicolumn{4}{|l|}{ Daily interaction with diverse customers } & 3.90 & .775 \\
\hline $\begin{array}{l}\text { Noting incidents related to colleagues with no } \\
\text { respect in diversity }\end{array}$ & & .724 & & 3.83 & 1.320 \\
\hline $\begin{array}{llll}\begin{array}{l}\text { Understanding } \\
\text { customers }\end{array} & \text { cultural differences of } & \\
\end{array}$ & & .652 & & 4.06 & .920 \\
\hline $\begin{array}{l}\text { Meeting daily customers with diverse } \\
\text { backgrounds }\end{array}$ & & .642 & & 3.99 & .912 \\
\hline $\begin{array}{l}\text { Interacting carefully with customers, as those } \\
\text { might be aware of my culture }\end{array}$ & & 620 & & 3.33 & 1.471 \\
\hline $\begin{array}{l}\text { Dealing daily with customers with diverse } \\
\text { cultural identities }\end{array}$ & & .601 & & 4.09 & .937 \\
\hline $\begin{array}{l}\text { Believing diversity helps my colleagues } \\
\text { understand customers' needs }\end{array}$ & & .514 & & 4.15 & 1.105 \\
\hline \multicolumn{4}{|l|}{ Understanding the value of diverse customers } & 3.74 & 1.193 \\
\hline $\begin{array}{l}\text { Understanding the value of diverse customer } \\
\text { profiles }\end{array}$ & & & .903 & 3.77 & 1.296 \\
\hline $\begin{array}{l}\text { Understanding the importance of diverse } \\
\text { customers }\end{array}$ & & & .900 & 3.72 & 1.252 \\
\hline KMO & .883 & $\begin{array}{l}\text { Bartl } \\
\text { Sphe }\end{array}$ & $\begin{array}{l}\text { tt's te } \\
\text { icity }\end{array}$ & st of & .000 \\
\hline Eigenvalues & 5.422 & $\begin{array}{c}1.46 \\
3\end{array}$ & $\begin{array}{c}1.24 \\
9\end{array}$ & & \\
\hline Variance explained (\%) (Total) & $\begin{array}{c}36.14 \\
8\end{array}$ & $\begin{array}{c}9.75 \\
4\end{array}$ & $\begin{array}{c}8.32 \\
7\end{array}$ & \multicolumn{2}{|c|}{$(54.229)$} \\
\hline Cronbach's alpha (Total) & .859 & .774 & .769 & \multicolumn{2}{|c|}{$(.855)$} \\
\hline
\end{tabular}

\subsection{Hypotheses Testing}

Aiming to test hypotheses proposed in operating model, Pearson correlation coefficient (PCC) was applied to present the direction of a relationship between two continuous 
variables (Table 3). Pearsons' $r$ is a statistic measure that explores linear correlation between two variables $X$ and $Y$, based on the method of covariance. Coefficient values can range between -1 and +1 . A value of -1 indicates a total negative linear correlation, 0 shows no linear correlation and +1 indicates a total positive linear correlation. Thus, this part of the analysis presents the results of the nine hypotheses of the current study.

\section{H1: There is a relationship between occupational status and handling diverse customers.}

The first Hypothesis, which exposed a relationship between how airline employees handle diverse customers regarding their occupational status (Full/Part time, Causal, Contract), was rejected $(r=0.01, d f=307, p=0.801)$. This finding confirmed that employees with different professional backgrounds and experiences can have a variety of attitudes in their workplace environment (Cheah, 2013).

\section{H2: There is a relationship between tenure in a company and handling diverse customers.}

The second Hypothesis, which proposed a relationship between the way that airline employees handle diverse customers and their tenure in the airline company, was not supported ( $r=0.00, d f=307, p=0.902)$. This aspect demonstrated that diverse employees with problem-solving skills provide alternative solutions to a competitive business environment (Cletus et al., 2018) as well as that organisations with experienced staff and diverse employees are better suited to serve diverse external customers in an increasingly global market (Patrick and Kumar, 2012).

\section{H3: There is a relationship between airline experience and handling diverse customers.}

The third Hypothesis, which exposed a relationship between the way that airline employees handle diverse customers and their total airline experience, was rejected ( $r=0.00, d f=307, p=1.000$ ). This finding emphasised the need for successful diversity management practices that can be compared between organisations and increase their impacts on employee productivity and job satisfaction (Patrick and Kumar, 2012).

\section{H4: There is a relationship between occupational status and daily interaction.}

In the communication field, the fourth Hypothesis, which proposed a relationship between the occupational status of airline employees' and their daily interaction with 
diverse customers, was not supported $(r=-0.04, d f=307, p=0.395)$. This asset did not confirm the ideas of Walia and Malik (2015) who recognised that workplace diversity provides employees with varied capabilities and skills that are essential components for enhanced communication, collaboration, and conflict resolution in a diverse workplace.

\section{H5: There is a relationship between tenure in company and daily interaction.}

The fifth Hypothesis, which proposed a relationship between the tenure of airline employees in an airline company and their daily interaction with diverse customers was not accepted $(r=-0.09, d f=307, p=0.086)$. In the light of growing diversity in companies and organisations around the globe, experienced employees tend to promote a safe area and comfortable atmosphere through diversity training programmes from which both parties (employees or managers and customerspassengers) can benefit. Even though $\mathrm{H} 5$ was not supported, airline companies should optimistically understand and determine employees' preconceptions in the workplace, as this trend proposed a way for creative and innovative ideas (Cheah, 2013). The last two non-supported hypotheses ( $\mathrm{H} 4$ and $\mathrm{H} 5$ ) emphasise that in modern-day organisations, skilled human resources interacting in a supportive workplace are usually treated with respect themselves and tend to treat their customers with respect as well (Foma, 2014), while communication maintains cohesion among colleagues and is considered crucial to the attainment of a company's goals, tasks, and management (Cletus et al., 2018).

\section{H6: There is a relationship between airline experience and daily interaction.} In contrast, $\mathrm{H} 6$ has been supported, as the findings confirm a slight negative linear relationship between airline experience and daily interaction with diverse customers $(r=-0.12, d f=307, p=0.032)$. This aspect derives mostly from the rights and responsibilities of both parties (experienced employees and customers) in the workplace and holds both groups accountable when dealing with diversity. In this context, Dhuppar (2015) suggested that diversity has the potential to unite and promote the collective strengths and inherent weakness of employees and referred that employees' different skills can be harnessed for better performance and productivity.

\section{H7: There is a relationship between occupational status and value of diverse customers.}


The seventh Hypothesis reported an insignificant relationship between values of diverse customers and airline employees' occupational status ( $r=-0.03, d f=307$, $p=0.554$ ). Employees' occupational status does not present a relationship with the values of diverse customers. Thus, it can be noticed that training and professional programmes will equip stakeholders with strategies and practices to address challenges that may arise from the "melting pot" of employees (Green et al., 2002). Despite employees' occupational status, leadership teams, managers, supervisors and staff composition are required to abstain from old habits and daily routines that discriminate people of diverse cultures both among employees of the same organisation and during the interaction of the said employees with their customers.

\section{H8: There is a relationship between tenure in company and value of diverse customers.}

The eighth Hypothesis showed an insignificant relationship between the values of diverse customers and the airline employees' tenure in a company ( $r=-0.07, d f=307$, $p=0.166)$. Hence, it can be assumed that the years that employees have been with their airline company did not reveal a correlation with the values of diverse customers. This aspect revealed that many organisations orientated fresh employees to familiarise themselves with the current operation climate and the existing workplace (Cletus et al., 2018), while diversity initiatives in the workplace should help employees to defend against resistance to change and provide to them a sense of belonging (Podsiadlowski et al., 2013).

\section{H9: There is a relationship between airline experience and value of diverse customers.}

The last Hypothesis also displayed an insignificant relationship between values of diverse customers and employees' experience in an airline industry $(r=-0.07, d f=307$, $p=0.164$ ). As current communication requires to deal with one another on a personto-person basis, experienced employees with cultural awareness, flexibility and effective communication skills are crucial for customer representatives to properly deal with the expectations and values of customers from different backgrounds. Taking into consideration the last three non-supported hypotheses, this study confirms many studies, which demonstrated that a humanistic approach of long-term benefits derived from diverse customers values assists companies and organisations to promote a safe place for both associates to communicate (Koonce, 2001); provide a better understanding of target groups; maximise the profits of business partners; and 
enhance potential employees' and customers' satisfaction (Cletus et al., 2018; Hunt, Layton and Prince, 2015; Green et al., 2002).

Table 3. Hypotheses testing

\begin{tabular}{|c|c|c|c|c|c|}
\hline $\mathbf{H}$ & & $\begin{array}{c}\text { Pearson } \\
\mathbf{r}\end{array}$ & df & $\mathbf{p}$ & Results \\
\hline $\mathrm{H} 1$ & $\begin{array}{l}\text { Occupational Status } \rightarrow \text { Handling diverse } \\
\text { customers }\end{array}$ & -0.01 & 307 & 0.801 & Rejected \\
\hline $\mathrm{H} 2$ & $\begin{array}{l}\text { Tenure in a company } \rightarrow \text { Handling diverse } \\
\text { customers }\end{array}$ & 0.00 & 307 & 0.902 & Rejected \\
\hline $\mathrm{H} 3$ & $\begin{array}{l}\text { Airline experience } \rightarrow \text { Handling diverse } \\
\text { customers }\end{array}$ & 0.00 & 307 & 1.000 & Rejected \\
\hline $\mathrm{H} 4$ & Occupational Status $\rightarrow$ Daily Interaction & -0.04 & 307 & 0.395 & Rejected \\
\hline H5 & Tenure in a company $\rightarrow$ Daily Interaction & -0.09 & 307 & 0.086 & Rejected \\
\hline H6 & Airline experience $\rightarrow$ Daily Interaction & $-0.12 *$ & 307 & 0.032 & Accepted \\
\hline $\mathrm{H} 7$ & $\begin{array}{l}\text { Occupational Status } \rightarrow \text { Value of diverse } \\
\text { customers }\end{array}$ & -0.03 & 307 & 0.554 & Rejected \\
\hline H8 & $\begin{array}{l}\text { Tenure in a company } \rightarrow \text { Value of diverse } \\
\text { customers }\end{array}$ & -0.07 & 307 & 0.166 & Rejected \\
\hline H9 & $\begin{array}{l}\text { Airline experience } \rightarrow \text { Value of diverse } \\
\text { customers }\end{array}$ & -0.07 & 307 & 0.164 & Rejected \\
\hline
\end{tabular}

*Correlation is significant at the 0.05 level (2-tailed)

\section{SUMMARY AND CONCLUSIONS}

Broadly translated authors' findings indicate that airline employees'- regardless of their working status (i.e., occupational status, tenure in company, airline experience)- seek a workplace with a friendly atmosphere that respects the diversity of both employees and customers, to feel more secure, be more effective and communicative with diverse customers and approach their values more successfully. According to the results, such behavioural attitudes highlight the need to consider the workplace as a safe area, which enhances the team spirit among organisation employees' and embraces the communication between employees and customers. Based on the above aspects, the authors emphasise the long-term advantages of diversity in the workplace, hoping that those patterns will be considered by employees, supervisors, and organisations, who are responsible for company success in today's global marketplace. This is achieved by implementing the right training methods both for employees that come from different backgrounds and for new employees in the industry. Education is important for the development of airline employees, as the industry itself is changing quite often. However, diversity executives cite the importance of having open-minded employees, who have a variety of creative, cultural, communicative, and problem-solving skills and operate over the comfort zone to achieve organisation's goals and customers' satisfaction. Hence, planning a diversity strategy should be the first step any modern- 
day organisation should explore prior to embarking anything related with a diverse workplace. Aviation jobs must be one of a kind as it requires a flexible approach towards customers and their mentalities. Employees involved in aviation operations come across different cultures within their working shift both with their customers and with their colleagues, as even the staff members working in an aircraft bring their own culture and diversity with them. In international airports, planes land daily transferring many different passenger profiles into an individual country. As the world keeps advancing, future studies are necessary to validate the kinds of conclusions that can be drawn from this investigation and to explore new ways to effectively manage diverse human resources and benefit from the interaction between employees' and diverse customers.

\section{ACKNOWLEDGEMENTS}

Authors would like to thank the employees of the participating airlines for their responses in the questionnaire survey and their constructive feedback.

\section{REFERENCES}

- Cheah, B. L.,(2013) Why workplace diversity is important for every organization. Career Guide 2013. Available from: https://bit.ly/2JweWEY/ (accessed on 01/03/2020).

- Cletus, H. E., Mahmood, N. A., Umar, A. and Ibrahim, A. D., (2018) Prospects and Challenges of Workplace Diversity in Modern Day Organizations. A Critical Review, HOLISTICA 9(2), 35-52.

- Deans, B (2018) Ten Reasons Why Employee Training Is Worth the Investment. Available from:

https://www.employmentlawhandbook.com/human-resources/ten-reasons-whyemployee-training-is-worth-the-investment/ (accessed on 29/10/2020).

- Dipak Prasad Bastola, D. (2020) The relationship between leadership style and aviaiton safety: a study of aviation industry. Journal of Air Transport Studies, 11(1), $1-26$.

- Dhuppar, S. (2015) Managing Workplace Diversity Challenges and Strategies. International Journal of Research, 2(3), 346-351.

- Esty, K. C., Griffin, R., and Schorr-Hirsch, M., (1995) Workplace Diversity. A Manager's guide to solving problems and turning diversity into a competitive advantage. Avon, MA: Adams Media Corporation.

- Foma, E.(2014) Impact of Workplace Diversity. Review of Integrative Business \& Economics Research, 3(1), 382-390.

- Green, K. A., Lopez, M., Wysocki, A., Kepner, K., Farnsworth, D. and Clark, J. L., (2002) Diversity in the Workplace: Benefits, Challenges, and the Required Managerial Tools. University of Florida, 1(4).

- Holloway, J. C., \& Humphreys, C. (2016) The Business of Tourism. Tenth Edition, Harlow, England; New York: Pearson Education Limited.

- IATA (2020) Industry Losses to Top $\$ 84$ Billion in 2020. Available from: https://www.iata.org/en/pressroom/pr/2020-06-09-01/ (Accessed 11/10/2020). 
- ICAO (2020) The World of Air Transport in 2018. Available from: https://www.icao.int/annual-report-2018/Pages/the-world-of-air-transport-in2018.aspx/ (accessed on 29/10/2020).

- ICAO (2020) Economic Development. SEP 2020: Air Transport Monthly Monitor. Global Key Figures. Available from:

https://www.icao.int/sustainability/Documents/MonthlyMonitor2020/Monthly\%20Monitor September 2020.pdf/ (accessed on 29/10/2020).

- Hunt, V., Layton, D., and Prince, S., (2015) Why diversity matters. Available from: https://www.mckinsey.com/business-functions/organization/our-insights/whydiversity-matters/ (accessed on 20/03/2020).

- Kapoor, C. (2011) Benefits of Diversity in the Workplace. Available from: http://benefitof.net/benefits-of-diversity-in-the-workplace/ (accessed on 15/12/2019).

- Keese, C. (2020). Cultural Diversity Training in the Workplace. Available from: https://smallbusiness.chron.com/cultural-diversity-training-workplace-43290.html/ (accessed on 29/10/2020).

- Koonce, R.(2001) Redefining diversity: It's not just the right thing to do; it also makes good business sense. Training and Development, 12(12), 22-23.

- Pallant, J. (2007) SPSS survival manual a step by step guide to data analysis using SPSS for Windows ( $3^{\text {rd }}$ edition) New York: McGraw Hill.

- Patrick, H. A. and Kumar, V. R., (2012) Managing Workplace Diversity: Issues and Challenges. SAGE Open 2(2): 2158244012444615.

- Podsiadlowski, A., D. Groschke, M. Kogler, C., Springer, and Van Der Zee, K. (2013) Managing a culturally diverse workforce: Diversity perspectives in organizations. International Journal of Intercultural Relations, 37(2), 159-175.

- Robinson, G. and Deschant, K. (1997) Building a business case of diversity. The academy of management executive, 11(3), 21-31.

- Ozbilgin, M., and Tatli, A. (2008) Global Diversity Management: An Evidence-based Approach. London. England: Palgrave.

- Velazquez, M. (2017) Advantages Of Diversity In The Workplace. Available from: https://www.ukessays.com/essays/commerce/advantages-of-diversity-in-theworkplace-commerce-essay.php/ (assessed on 28/2/2020).

- Walia, M.S. and Malik, R. (2015) Workforce Diversity Management: Essence of Modern Organizations. Editorial Board.

- Yu-Hern Chang, M.-Y. L.-C. (2013). Effects of airlines "cabin crew training on their flight safety performance" . Journal of Air Transport Studies, 4(1), 1-114.

\section{AUTHORS' BIO}

Dr Maria P. Doumi (corresponding author) is Academic Faculty Lab Instructor at the School of Business Administration of the University of the Aegean with expertise in "Quantitative Methods in Regional Analysis and Tourism". Her research interests include applications of quantitative methods in regional and economic development as well as study of the contribution of tourism to sustainable development of a region. Part of her research work has been published in international academic journals and was presented at international scientific conferences. Email: mdoumi@aegean.gr

Ioannis K. Vellios holds an MSc degree in Tourism Business Administration from the Hellenic Open University of Patras. His research interests include Human Resources Development and Recruitment within multicultural environments and methods promoting Equality-Diversity and Inclusion for employee's development at workplace. $\mathrm{He}$ is an experienced individual within the aviation/airline industry, as he has worked in several departments both in Greece and abroad. Email: ioannisvellios@hotmail.com 
Konstantinos M. Mouratidis holds an MSc degree in Tourism Development Strategy from the University of the Aegean. His research interests include Tourism Planning, Special and Alternative Forms of Tourism, Sociology of Tourism. Several of his papers have been presented in the proceedings of many international conferences and he has also published chapters in some Tourism, Business \& Management Books. Email: mouratidis.konstantinos@outlook.com.gr 